\title{
EL ARTE TEXTIL AÓNIKENK: POSIBLES MODOS DE ADOPCIÓN Y ALGUNAS PARTICULARIDADES
}

PATRICIA M. MÉNDEZ

\section{RESUMEN}

Se presentan los fundamentos que permiten afirmar que algunos grupos aonikenk incorporaron la práctica textil hacia finales del siglo XVIII y que las particularidades técnicas de tal práctica son deudoras de las de los araucanos. También se plantean algunas hipótesis explicativas sobre los modos en que estos grupos meridionales adoptaron la textilería y sus dificultades implícitas. Asimismo se indaga sobre los tejidos que elaboraron, los destinos que dieron a los mismos hasta la década de 1880 y se plantea una posible razón de su adopción. Paralelamente se refutan algunas suposiciones arraigadas entre los estudiosos de las culturas indígenas patagónicas y de la textilería de la región, relacionadas con las causas de la incorporación del arte textil por los aonikenk y las limitaciones inherentes a la carencia de ovinos.

Para el análisis se emplean documentos históricos escritos y gráficos así como también resultados de investigaciones etnográficas. Se concluye que el desarrollo del arte textil entre los aonikenk habría estado estrechamente relacionado con la actividad ecuestre incorporada hacia la misma época.

PALABRAS CLAVES: aonikenk, textilería, equitación, relaciones interculturales, 1780-1880.

\section{THE TEXTILE AÓNIKENK ART: POSSIBLE MODES OF ADOPTION AND SOME PECULIARITIES}

\begin{abstract}
We present the foundations that support the conclusion that some groups aonikenk joined the textile practice in the late eighteenth century and that the technicalities of such practice are indebted to those of the araucanians. It also raises some explanatory hypotheses about the ways in which these southern groups have adopted the textiles and its difficulties involved. It also explores the tissues produced, the fates that were given to them until the 1880 s and poses a possible reason for its adoption.
\end{abstract}

Licenciada en Historia. Investigadora en el Proyecto Tierradentro, Ministerio de Industria, Agricultura y Ganadería de la Provincia de Chubut (Argentina). Investigadora en el Proyecto Interculturalidad y arte textil como símbolo de identidad, Ministerio de Educación de la Provincia de Chubut (Argentina). Correo electrónico: patitomendez@yahoo.com.ar 
Parallel some assumptions are refuted rooted among scholars of indigenous patagonian cultures and of textiles from the region, related to the causes of the incorporation of textile art by aonikenk and limitations inherent in the lack of sheep.

For the analysis charts and written historical documents are used as well as ethnographic research results. It concludes that the development of textile art among aonikenk would have been closely associated with equestrian activities built around the same time.

KEYWORDS: aonikenk, textiles, horse riding, intercultural relationships, 1780-1880.

\section{INTRODUCCIÓN}

Hasta hace aproximadamente dos décadas, los estudios acerca de los grupos indígenas de la Pampa y la Patagonia argentina los caracterizaron como unidades étnicas aisladas cuyas culturas habían permanecido inmutables a lo largo del tiempo y que eran diferenciadas a partir de inventarios de sus rasgos. Esto condujo, por un lado, a la conformación de estereotipos culturales según los cuales cualquier modificación cultural era apreciada como una aculturación o, en los casos más extremos, como una contaminación cultural; y por otro, a efectuar exámenes analíticos de los rasgos culturales sin tener en cuenta los que eran considerados significativos para los integrantes de cada grupo e ignorando los múltiples aspectos de la integración cultural.

En los últimos años, numerosos trabajos han mostrado un panorama muy diferente que ha estado vinculado a un cambio metodológico, que implica la realización de los estudios históricos mediante el empleo de nuevas fuentes de información y que considera a los grupos aborígenes y a sus culturas como entidades históricas y, por lo tanto, cambiantes a lo largo del tiempo. Sin embargo, en cuanto a la comprensión de la cultura como algo más que una simple enumeración de rasgos propios o adquiridos, los estudios históricos sobre las agrupaciones indígenas de la Patagonia aún están en ciernes. Si bien varios han referido sobre los cambios culturales producidos al interior de las distintas parcialidades de la región a lo largo del tiempo, sus trabajos abundan en descripciones pero adolecen de esfuerzos explicativos. Como afirma Abraham Monk en su estudio preliminar al trabajo de Franz Boas (1964): Probar que un trazo cultural ha sido prestado o incorporado es un esfuerzo descriptivo inconducente que no trasciende los efectos de la mera cronología. Lo significativo sería revelar por qué ciertos trazos han sido aceptados con mayor facilidad, por qué otros han sufrido resistencias y rechazo y por qué unos fueron incorporados con diferente sentido, con formas modificadas. Estos interrogantes apuntan indudablemente hacia la historia específica y única de cada grupo. Con el presente trabajo pretendemos realizar un aporte en este aspecto, es decir, considerando al contenido cultural como parte integrante de un conjunto dentro del cual adquiere una significación y una forma particular ${ }^{1}$. Las limitaciones en este sentido son muy grandes si tenemos en cuenta que quienes elaboraron los documentos existentes para el análisis fueron ajenos a las culturas indígenas; sin embargo, ello no impide el planteamiento de hipótesis a partir de los datos recabados.

El rasgo cultural analizado es la textilería o práctica textil, entendiendo como tal a toda elaboración producida en forma manual y no seriada, realizada exclusivamente en telar y que se distingue del trenzado por la formación mecánica del cruce entre los hilos de la urdimbre y de la trama (Chertudi y Nardi 1961). El grupo social estudiado comprende a los aonikenk o tehuelches meridionales, denominaciones éstas dada por algunos estudiosos y que congrega a diferentes parcialidades indígenas en base a rasgos lingüísticos

1

Consideramos a la cultura como un modelo heurístico de saberes y prácticas de antaño más que una herencia recibida pasivamente y sin reflexión alguna. La cultura es en parte heredada y en parte construída. Por lo tanto, es un proceso dependiente de una herencia pero también del contexto histórico y de las interacciones sociales. Estimamoss que la cultura debe ser definida por su uso y no por su origen, como hecho y no como esencia, como posición relacional y no como sustancia. Lo relevante es la relación de diferencia o de contraste respecto de otras culturas, lo cual implica una concepción dialéctica de las relaciones sociales (Barth 1975, Jenkins 1996, Boccara 2000). 
y a ubicaciones geográficas (Vignati s/f, Escalada 1949, Casamiquela 1965, Martinic 1995). Estas consideraciones habrían permitido a Casamiquela (1965) establecer la existencia de parcialidades diferenciadas entre los aonikenk y que ocupaban espacios distinguibles, razones por las cuales las denominó respectivamente boreal y meridional: la primera de ellas habría estado ubicada entre el río Chubut y el río Santa Cruz, y la segunda entre éste último y el estrecho de Magallanes. Este espacio será el considerado para el análisis, teniendo siempre en cuenta las modificaciones en la conformación y ubicación de esos grupos indígenas a lo largo del período estudiado, el cual se inicia con los primeros documentos que refieren sobre la actividad textil entre los aonikenk y concluye en la década de 1880, momento en que las Campañas de Conquista del Desierto produjeron profundos cambios en las culturas de los grupos indígenas de la Patagonia, marcando un antes y un después en el desarrollo de las mismas.

Desde tiempos prehistóricos, los aonikenk, así como sus vecinos de las regiones inmediatas de la Patagonia argentina, se especializaron en el trabajo con pieles y cueros, materiales que ellos emplearon para la realización de numerosos elementos útiles a su forma de vida: desde sus moradas hasta su vestimenta, los elementos de su montura y numerosos utensilios domésticos. Son varios los estudios que han analizado con mayor o menor profundidad las particularidades de ese arte, el cual aún perdura entre algunos pobladores de las zonas rurales de esa región (Gómez Otero s/f, Irusta de Benbassat 1986, Caviglia 2003, Finkelstein 2008). Sin embargo, son escasos los trabajos que han indagado sobre las particularidades del arte textil entre esas agrupaciones patagónicas, y menos aún entre los aonikenk. Varios han referido sobre la posible procedencia de la tejeduría aonikenk y han planteado algunas hipótesis sobre la forma en que este arte habría sido adoptado. Pero ello se ha efectuado en el marco de estudios más amplios y, por eso mismo, no se ha profundizado en la temática (Gómez Otero s/f, Palermo 1994, Martinic 1995). Probablemente esta carencia ha dado lugar a la realización de las ampliamente difundidas clasificaciones de los grupos aborígenes a partir de ciertos rasgos culturales considerados significativos por algunos estudiosos. De esta manera, en un marco atemporal, la cultura tehuelche se habría homogeneizado bajo su caracterización de productora de elaboraciones en pieles y cueros, distinguiéndose de la cultura mapuche, que realizaba prendas tejidas en telares, etc.

Datos hallados en algunos documentos escritos a los que se hace referencia a lo largo de este trabajo, así como el marco teórico empleado, permiten relativizar tales afirmaciones a partir de un análisis temporal y espacial que muestra la naturaleza intrínsecamente cambiante de toda sociedad humana y la adaptación de su bagaje cultural. Específicamente, a través de ellos se visualiza la adopción del arte textil por los aonikenk durante el período estudiado, la forma en que ésta posiblemente se llevó a cabo, las características que adquirió su producción textil y los empleos que ellos dieron a los tejidos, todo lo cual sólo puede ser comprendido en relación con los restantes aspectos culturales de esas agrupaciones y en función de sus vinculaciones con otros grupos.

\section{REFERENCIAS SOBRE LA ADOPCIÓN DE LA TEXTILERÍA POR LOS AÓNIKENK}

La primera referencia que hemos hallado sobre la existencia del arte textil entre los aonikenk corresponde a Antonio de Viedma y data de 1783. Este autor asegura que los indígenas de las proximidades de San Julián Se ciñen la cabeza con una cinta de lana como de dos dedos de ancho, tejida por ellos de varios colores (Viedma 1837: 69).

El segundo informe corresponde a los misioneros anglicanos Coan y Arms, quienes refieren sobre la existencia de una práctica textil entre algunos indígenas que habitaban el territorio próximo al estrecho de Magallanes a fines de 1833 y comienzos de 1834. Relata Coan: Salimos para ver entre ellos el proceso de tejido. Vimos en el telar una tela destinada a ser una colcha y a la tejedora dedicada a su trabajo [...] El hilo con el que se hacen estas colchas es devanado de la lana de guanaco. Su fibra es larga y suave. Se lo extrae con los dedos $y$ es retorcido por medio de una caña sostenida en una mano. Se lo colorea con varios tipos de arena, que se consiguen en el interior del país (Coan 2006[1880]: 122-123). En su diario de viaje, también Arms asegura que las mujeres indígenas cosen en un proceso muy tedioso, tejen de manera igualmente laboriosa (Coan 2006[1880]: 199). 
Estos autores también ofrecen algunos datos sobre las particularidades técnicas del tejido: sostiene Coan que El telar se construye colocando dos postes verticales en el suelo y se sujetan dos palos horizontales sobre aquéllos, uno sobre otro, a una distancia igual al largo que se quiere dar a la colcha, que en este caso era de un metro treinta. La urdimbre se ata a estos palos en cada extremo. El proceso de tejido es lento y tedioso. La trama es atada con una agujeta o varilla que hace de bobina. La tejedora se sienta en el suelo delante del telar y, con otra varilla, separa los hilos de la urdimbre y entonces, con un cañón de pluma de avestruz como lanzadera, lo pasa por los espacios abiertos. Entonces la varilla es extraída, después de servir como parte de la estructura y la urdimbre es separada como antes. Este proceso es continuado hasta que la colcha está completa, lo que es sólo después de muchos y agotadores días, ya que la artesana apenas logra unas pocas pulgadas por día (Coan 2006[1880]:122-123). La descripción de Arms, aunque menos pormenorizada, también ofrece algunos datos técnicos sobre el proceso de tejido y también sobre el hilado: $\mathrm{Su}$ forma de tejer es ovillando la lana en una gran madeja y pinchándola con una agujeta que se coloca perpendicularmente y que es estirada con la mano que jala de la lana hacia fuera, mientras la otra sostiene [ilegible]. La agujeta tiene una bola en la punta y se mueve con facilidad. Es hecho así como se hace una cinta en N.A. golpeada con un cuchillo de madera (Ibíd.: 277).

El otro testimonio corresponde a Doroteo Mendoza, quien tres décadas más tarde relata que las mujeres indígenas pertenecientes a la agrupación liderada por Casimiro y parcialidades aledañas a la zona del río Santa Cruz por lo regular, son laboriosas; se ocupan de hacer tejidos, mantas, fajas y cintas de lana, hilo y seda bastante finos y de labores curiosas; pero, como carecen de lana, se valen de deshilar las bayetas y de la filana a la rueca y el huso, tuercen el hilo de varios colores, más o menos fino, según lo precisan.

El aparato para tejer es muy sencillo: consiste en dos palos, apartados el uno del otro a la distancia y ancho de la tela que han de trabajar. En ellos envuelven el hilo, con las separaciones de los colores, bien estirados; entrelazan luego, un peine con hilos cortos que sirven para la operación de apartar los hilos de la urdimbre y luego, con unos ovillos de diferentes hilos de colores, hacen la trama y bordados al telar que dibujan con primor y, a veces, mucho gusto (Mendoza 1965: 67-68). Tal como sostiene Vignati en las notas consignadas en el escrito de Mendoza, probablemente existan algunos errores en estas aseveraciones del autor: primeramente, resulta sumamente extraño que se empleen hilos de seda para tejer en esa región; en segundo lugar, el término filana resulta desconocido en la lengua española.

La cuarta alusión al arte textil entre los aonikenk corresponde a Musters, quien hacia la década de 1870 refiere que las mujeres aonikenk tejían de la misma manera que el marinero fabrica un pallete de los llamados "de sable" (Musters 2005 [1911]: 204). Según el Diccionario Marítimo Español publicado en 1864, se denomina "pallete á sable" a un tejido de meollar o de cordones de cabo que se teje pasando un cabito llamado madre por entre varios cordones paralelos, y azocándolo a golpes con una pieza de madera semejante a la hoja de un sable (Lorenzo, Murga y Ferreiro 1864). Este método es el empleado en la actualidad y desde hace siglos entre las tejedoras de la Araucanía en sus telares. Asimismo, el telar descripto por Coan corresponde al de uso más extendido en esa región y que ha sido denominado telar vertical por numerosos estudiosos de la textilería americana o telar mapuche como forma más extendida (Mendez 2009a). Es muy probable que el telar observado por Arms haya sido el mismo que describió Coan debido a que fueron compañeros de viaje y estadía entre los aonikenk. En cuanto a la referencia de Mendoza, es demasiado vaga como para arribar a alguna identificación definitiva, aunque es posible suponer que es la misma tradición textil que la proveniente de la Araucanía.

$\mathrm{Si}$ aceptamos la veracidad de estos relatos, suponemos que hacia la octava década del siglo XVIII algunas agrupaciones aonikenk realizaban tejidos y que su técnica probablemente era deudora de la tradición textil proveniente de la Araucanía. El conocimiento de dicha práctica textil por los aonikenk resulta comprensible si consideramos que ellos mantuvieron relaciones con los indígenas pampeanos y norpatagónicos desde los primeros tiempos históricos e incluso prehistóricos (Casamiquela 1965, Hadjuk 1981-82), quienes a su vez 
estuvieron en contacto con las parcialidades araucanas realizadoras de tejidos (Palermo 1991, 1994). Asimismo, la incorporación de los equinos traídos por los españoles y adoptados prontamente por los indígenas permitió -entre otras cosas - efectuar mayores desplazamientos territoriales en menos tiempo e implicó que los aonikenk también mantuvieran contactos directos con los araucanos y grupos araucanizados a ambos lados de la cordillera (Cox 1999 [1863]: 239). El inicio de la etapa ecuestre de los aonikenk, junto con la fundación de colonias hispanas en las costas patagónicas hacia el siglo XVIII, favoreció el crecimiento de esta movilidad indígena cuyo objetivo principal fue comercializar sus productos y adquirir los bienes deseados: Este fenómeno generaba una constante circulación de bienes y personas por rutas fijas (las 'rastrilladas') y complejos procesos de intermediación; los productos solían pasar por varias manos antes de alcanzar su destino final, ocasionando además el funcionamiento de verdaderas ferias indígenas estacionales. La más conocida era la de la zona de los pasos cordilleranos del centro de Neuquén [...] donde a comienzos del otoño austral (marzo) convergían indígenas de distintas etnias: grupos procedentes de la Pampa, con arreos de ganado; la población de la zona, con sus productos agrícolas, ganaderos, de recolección y textiles; tehuelches meridionales con cueros, bolas de piedra para boleadoras, etcétera (Palermo 1991: 169).

Este proceso habría generado cambios culturales entre las agrupaciones indígenas intervinientes, aunque en diferentes grados. Para Palermo (1991) la intensidad de los cambios culturales y el grado de dependencia del comercio para reproducir su forma de vida estaría en relación con la ubicación geográfica de esas agrupaciones. Es por ello que, para este autor, puede hablarse de la existencia - desde el siglo XVII - de un único sistema poliétnico que incluía a las agrupaciones del norte de la Patagonia, de la Pampa y también de la Araucanía, pero en el cual los aonikenk sólo tenían una participación marginal durante la época colonial. Entonces, según esta hipótesis, antes del surgimiento del fuerte Bulnes en el año 1843, los aonikenk se relacionaron con los asentamientos españoles en la costa patagónica y con los grupos indígenas de la Patagonia septentrional, así como también de la Pampa y la Araucanía, $e$ incluso tuvieron contactos ocasionales con naves de variada procedencia que incursionaban por el estrecho de Magallanes. Pero la asiduidad de estos contactos habría sido baja en relación con los nativos de más al norte: éstos articularon diversos sectores de su sociedad con las restantes agrupaciones a tal magnitud que es posible caracterizar la relación como un sistema poliétnico; los aonikenk, en cambio, mantuvieron relaciones más o menos intensas con esos grupos sin haber llegado a una dependencia o interdependencia con los mismos, y sin variar su forma de vida a pesar de haber experimentado cambios culturales.

Es por esto último que los testimonios sobre la práctica textil entre los aonikenk resultan sorprendentes: hacia la época analizada, ellos eran grupos de cazadores-recolectores con una alta movilidad dependiente, la mayoría de las veces, de la posibilidad de obtener su principal fuente de sustento, el guanaco. La alta movilidad de estos grupos aborígenes y el tiempo que requería -y requiere- la confección de tejidos habría condicionado grandemente la tarea. El traslado de los telares con las confecciones inconclusas requeriría de una gran destreza para no echar todo el trabajo a perder: habría que evitar el cruce de los hilos de la urdimbre y del lizo, mantener la tensión del tejido inconcluso, etc. Por otra parte, la geografía del país aonikenk carece de árboles de donde obtener los palos rectos y fuertes necesarios para la confección del telar empleado, puesto que los mismos deben ser capaces de soportar la presión que se ejerce sobre el hilo de la trama y la tensión de los hilos de la urdimbre. Sin embargo, este último inconveniente probablemente fue rápidamente sorteado, puesto que los palos de tales características pueden haberse conseguido en los mismos lugares y momentos en que se obtenían los palos para los toldos y otras necesidades. Coan refiere que en una oportunidad El capitán Louis salió y volvió con un caballo cargado de palos y estacas para colgar de ellos la carne fresca. La madera se parece a la fresa silvestre. Debe haberla traído de lejos, ya que ha estado fuera casi todo el día (Coan 2006[1880]: 76-77). La dificultad que implicaba conseguir estos palos se evidencia en el interés por su preservación: más adelante Coan relata que, luego de un traslado del campamento de la agrupación con la cual convivían él y Arms, nuestra bondadosa madre india [la madre de Louis, un líder del grupo] con su hijita volvían al último lugar donde paramos para 
traer algunas estacas y palos que habían dejado, ya que el [día] 17 nuestros caballos habían estado sobrecargados, pero los necesitábamos (Coan 2006[1880]: 81).

Un documento gráfico presentado por Martinic, que fue elaborado cuatro años más tarde de la estadía de Coan y Arms entre los aonikenk resulta revelador al respecto. Afirma Martinic: en lo que parece haber sido una excepción al presunto tabú que vedaba la presencia de los cazadores esteparios en los campos forestales (monte espeso), se cuenta con una evidencia gráfica correspondiente a 1838 [del dibujante Le Breton, de la expedición de Dumont D'Urville] que muestra a un grupo de aóni-kenk en un sector boscoso tan austral y de difícil penetración a la sazón como lo era la comarca del río San Juan (el Sedger de los mapas antiguos), y que debe explicarse únicamente por la extracción de varas de canelo (Drimys winteri), naturalmente rectas, resistentes y con "perchas" regularmente dispuestas a lo alto, muy a propósito para su empleo en los toldos, pues madera para combustible la tenían a mano los indios más al norte, en la comarca de Cabo Negro, entre otros sitios forestados (Martinic 1995: 88). A partir de estos documentos podemos afirmar, entonces, que si bien el acceso a palos adecuados para la confección de los telares habría resultado dificultoso, de ninguna manera debe considerarse imposible: el aprovisionamiento de los mismos habría coincidido con la obtención de los palos necesarios para los toldos y otros usos. Si bien sólo algunos grupos aonikenk podían acceder a estas zonas (por cuestiones de derechos territoriales, lejanía, etc), sabemos de las usuales alianzas existentes entre ellos que habrían facilitado ese acceso (Martinic 1995). Por otra parte, resultaba un hecho usual - y hoy en día, en algunas regiones de la Patagonia lo continúa siendo - el recorrido de grandes distancias para la búsqueda y selección de los palos adecuados a ser empleados en los telares. En algunas familias, tal esfuerzo es justificado por el hecho de que los mismos (junto con los demás utensilios) son transmitidos a las sucesivas generaciones de mujeres (Mendez 2009a).

Asimismo, y como ha sido planteado por algunos autores, la inexistencia del ganado ovino entre los aonikenk hasta finales del siglo XIX también podría presentarse como un limitante en el desa- rrollo de la textilería (Palermo 1991:165; Mandrini y Ortelli 2006:29). Sin embargo, y contrariamente a esta conjetura, estimamos que ni la posesión de ovinos ni la adquisición de lana de esos animales era necesaria (menos aún imprescindible) para poder desarrollar la práctica textil. Tal como fue citado oportunamente, los hilos obtenidos del deshilado de algunas telas (como por ejemplo la bayeta) y el pelo de guanaco eran empleados en la confección de los tejidos. Si bien el primero resultaba una innovación posible gracias al contacto con las manufacturas europeas, el empleo del pelo de guanaco por lo aborígenes de la región de la Araucanía se remite a los tiempos anteriores a la conquista española de la América del Sur (Méndez 2009a). Tal práctica continuó vigente entre las agrupaciones al este de la cordillera y norte de la Patagonia a lo largo del siglo XIX y XX (Millán de Palavecino 1963; Kermes 1893; entre otros) llegando incluso hasta la actualidad (Méndez 2009a). Es por esta razón que no consideramos a la carencia de ovinos entre los aonikenk como una posible limitación en el desarrollo de su tejeduría: la principal fuente de su sustento (los guanacos) podían brindar la materia prima para sus tejidos a la vez que ofrecían cierta variedad de colores naturales para la realización de las ornamentaciones de los mismos.

Paralelamente a los testimonios citados que refieren sobre la práctica textil entre los aonikenk, existen otros que permiten vislumbar un panorama sumamente diverso dentro de las diferentes parcialidades. Como ejemplo, Jorge Barne registró a mediados del siglo XVIII que los navegantes del bergantín San Martín estuvieron en contacto con varios indígenas a la altura del puerto San Julián. Según el testimonio de éstos, los nativos les ofrecieron muchas de aquellas pieles, piedras bezares, lana de huanaco, aunque algunos dicen que era de vicuña; pero como todo naufragó no se ha podido averiguar la realidad y distinción de dicha lana. Uno de los caciques traía su poncho bueno, y también tal cual traía poncho; pero estos los cuidaban mucho (Barne 1837:17). Este documento informa que, además de las pieles, los indígenas ofrecieron lana de camélido a los navegantes. Pero también abre nuevas cuestiones: ¿esta lana fue obtenida de los camélidos por ellos mismos o fue adquirida? ¿Era empleada sólo para comerciar y obtener, entre otras cosas, los ponchos que vestían 
tales nativos o también era empleada para realizar dichas prendas?

Un siglo más tarde, Musters aseguraba que los indígenas de la región meridional de la Patagonia con quienes estuvo en contacto no aprovechaban la lana del guanaco, sino que tejían las vinchas para la cabeza [...] con hilo de telas deshiladas obtenidas por trueque en las colonias, o de sus vecinos araucanos (2005[1911]:204). Según este viajero: Es indudable que la lana [de guanaco] podría ser aprovechada con fines mercantiles, porque su contextura es muy delicada y actualmente tiene valor en Chile, donde se la teje para hacer ponchos que se venden a altos precios (Ibíd.:153).

En una carta del cacique Antonio (líder de un grupo integrado por tehuelches septentrionales y meridionales) al Señor Jones, Superintendente de la Colonia del Chupat, fechada en 1865 le informa que: Vendemos también pieles de guanaco y, si ustedes desean llevaremos además lana de guanaco; pero nuestro trabajo es hacer mantos de guanaco ("quillangos"). Nuestras mujeres los hacen (Claraz 2008:178). Nada informa acerca de la confección de tejidos, así como tampoco lo hacen Moreno, Lista y Schmid, entre otros que convivieron con algunos aonikenk en el siglo XIX, quienes tampoco hacen referencia al comercio de la lana de guanaco.

De esto es posible deducir que algunos grupos aonikenk realizaban textiles con la lana de los guanacos, otros los hacían con hilos de telas, otros comercializaban la lana de guanaco y otros no efectuaban ninguna de las dos actividades, no siendo excluyente, probablemente, la combinación de algunas de estas tareas dentro de un mismo grupo. Por lo tanto, estimamos que hacia el periodo analizado sólo algunos grupos aonikenk adoptaron la textilería o posiblemente lo hicieron en diferentes momentos. Cabe preguntarse, entonces, por qué razones se habría producido este cambio cultural y de qué manera se habría llevado a cabo, teniendo en cuenta que, como han señalado varios autores (Palermo 1994; Martinic 1995; Ortelli 1996; entre otros), la adopción de nuevos elementos culturales no es instantánea ni es un resultado inherente de todo contacto entre culturas diferentes, sino que requiere un proceso de evaluación sobre la conveniencia o no de la incorporación de determinadas creaciones. Trataremos de responder a estas cuestiones en los siguientes apartados.

\section{POSIBLES MODOS DE ADOPCIÓN DE LA TEXTILERÍA POR LOS AÓNIKENK}

En este punto plantearemos algunas hipótesis que nos permitan explicar de qué manera el saber textil fue incorporado por algunos grupos aonikenk. La primera de ellas propone la existencia de un proceso de enseñanza y aprendizaje entre las mujeres tejedoras del norte de la Patagonia y las aonikenk, el cual se habría producido en el momento de los intercambios comerciales. Estimamos que ello habría implicado numerosas dificultades si tenemos en cuenta que, a pesar de que el telar utilizado para realizar estos textiles es rústico y bastante sencillo, su empleo no es tal. Varios testimonios dan cuenta de que la realización de tejidos era una actividad ardua y dificultosa (Coan 2006[1880]; D’Orbigny 1998 [1843]; Kermes 1893; Joseph 1931; Onelli 1916; entre otros) y que su aprendizaje era un proceso complejo y lento que implicaba no sólo el manejo del telar, sino también el proceso de escarmenado e hilado de la lana o el pelo (Joseph 1931; Wilson 1992; Mendez 2009a). Incluso la realización de los textiles más sencillos demoraba varios días, implicando que el desarrollo de la enseñanza fuese prolongada: $E l$ aprendizaje en las rucas ofrece serias dificultades. Las tejedoras gastan una o dos semanas para confeccionar un choapino, otro tanto emplean para tejer una manta o lama y varios días necesitan para terminar un trarihue y esto en los casos más favorables [...] Diez veces al día interrumpe su labor para entregarse a otros quehaceres urgentes y diez veces lo reanuda (Joseph 1931:4). Debido a que el aprendizaje de la tejeduría se realizaba en el mismo proceso de producción (la novicia debía mirar e imitar los movimientos de su maestra al tejer, al tiempo que ambas realizaban los tejidos), eran necesarias numerosas imitaciones y correcciones antes de que la aprendiza estuviera en condiciones de realizar un tejido por su propia cuenta. Asevera Wilson al respecto: Al parecer, aprender los conocimiento de la maestra siempre es un tránsito 'doloroso' donde las jóvenes se sienten afectadas por el trato riguroso que ésta [la maestra tejedora] les da. Por ello, es importante que las aprendices tengan ciertas cualidades personales que faciliten este aprendizaje, como por ejemplo: haber visto tejer cuando niñas, tener 'buena cabeza' (capacidad para memorizar las técnicas y los diseños) (Wilson 
1992:9). Todas estas consideraciones, así como también otras cuestiones técnicas relacionadas con el nivel de destreza de la tejedora, continúan aún vigentes entre quienes practican este arte (Mendez 2009a).

Por otra parte, los primeros tejidos realizados por las novicias suelen ser más sencillos de realizar, de tamaño pequeño y con diseños lisos, de listas o peinecillos; los dibujos más complejos, por el contrario, son siempre realizados por las tejedoras más expertas y requiere de mucha práctica manual y también memorística. Asimismo, el armado de la urdimbre para piezas de gran tamaño resulta una tarea compleja que la mayoría de las veces requiere del trabajo de dos tejedoras o una tejedora versada y su aprendiza para realizarlo (Ibíd.). Es por esto que, si las aonikenk eran novatas en este arte, no habrían estado en condiciones de realizar amplios tejidos con variadas combinaciones de colores y complejas figuras, tal como ha testimoniado Coan: aunque el proceso es lento, la artesanía es maravillosa. Muchas tinturas y una gran variedad de figuras son entretejidas en la textura. A menudo, estas figuras son de buen gusto y muestran mucho genio natural en quien las hace (Coan 2006[1880]: 123). Sólo imitando a una tejedora experimentada durante algún tiempo, y luego de prácticas de tejidos más sencillos, hubiese sido posible adquirir tal destreza. Por lo tanto, la diversidad de colores y de figuras presentes en ese tejido da a entender que quien tejía era alguien que tenía cierta práctica en este arte, una tejedora experimentada y no una aprendiza.

El análisis sobre las dificultades en el aprendizaje de esta tejeduría (que incluye la selección y obtención de la materia prima, el escarmenado $e$ hilado, el urdido y el tejido propiamente dicho) y las particularidades de las confecciones descriptas por el documento referido, plantea algunas dudas sobre la posibilidad de que tal destreza haya sido aprendida en el corto período que duraban los intercambios (Musters 2005[1911]:136, 275, 283). Sin embargo, y a pesar de que no hallamos referencias sobre este proceso de enseñanza-aprendizaje durante los intercambios, consideramos que tal hipótesis no debe ser descartada.

Otra posible conjetura supone la existencia entre los aonikenk de mujeres provenientes de agrupaciones con tradición textil, quienes habrían transmitido tal arte a las mujeres de la agrupación receptora. Es sabido que los contactos entre los diferentes grupos favorecían las relaciones entre los individuos pertenecientes a las distintas parcialidades y daba lugar a la concreción de casamientos. Estas uniones generaban lazos familiares entre las agrupaciones, las cuales, obligadas por la solidaridad del parentesco, prestaban apoyo y protección, favorecían contactos con determinadas zonas, etcétera, a quien se ocupaba de la circulación de bienes. En sentido más amplio, este mecanismo servía de igual modo para las alianzas de tipo político entre jefes de distintas tribus o parcialidades (Palermo 1991:176). Las referencias históricas al respecto son abundantes, aquí sólo se citarán algunas de las que refieren sobre las vinculaciones entre las parcialidades tejedoras y los aonikenk:

Barne informa que el 17 de enero de 1754 llegaron a la ciudad de Buenos Aires 18 o 20 indios pertenecientes al grupo del cacique Bravo, cuyo territorio abarcaba las sierras del sur de la Provincia de Buenos Aires. Barne preguntó a esos indios si comprendían las palabras que los marinos habían tomado nota en su contacto con los indígenas de San Julián (actual Provincia de Santa Cruz). Uno de ellos las comprendió. Sorprendido, Barne le preguntó cómo era posible que, perteneciendo al grupo del cacique Bravo podía entender la lengua de indígenas que habitaban lugares tan distantes de los de su partido. El aborigen le respondió que porque era de su nación, nombrada Tehuelches, de la cual se separó pequeño y vino a parar al partido de dicho cacique (Barne 1837: 18). Y agregó que su cacique [Bravo] tenía tratado casamiento de una hija suya con uno de los caciques más próximos a su partido, y que estos, aunque en muy larga distancia, se comunican con los que andaban por la costa (Ibíd.).

Otro ejemplo es el del cacique "Negro" o Chanel, del río Colorado, que hacia 1780 tenía una esposa 'auca' (denominación dada a los grupos araucanos o araucanizados) y un primo cacique en el golfo de San Julián, territorio tehuelche meridional (Palermo 1991: 176).

En una carta fechada en 1863, Stirling relata que se encontró con un grupo de indígenas en Weddell Bluff (en la margen derecha del río Santa Cruz, muy próximo a su desembocadura) entre quienes había un miembro de las tribus del norte [...] El otro hombre pertenecía a las tribus del sur, 
de unos sesenta años pero corpulento y erguido, padre de uno de los muchachos y cuya madre, araucana, había muerto pocos años antes en Puerto Deseado. También la niñita era hija suya; la madre, perteneciente a la tribu fueguina de los Alikhoolip, había sido ultimada [...] La [otra] mujer era hijastra de este hombre e hija de la muerta Alikoolip, y de un marido anterior a ésta (Schmid 1964:144-145).

En el estudio preliminar que realizó Casamiquela a la obra de Claraz Viaje al Río Chubut, informa que Paillacán era "manzanero", es decir, surneuquino, pero no araucano, y su mujer, madre de Joyel, era tehuelche meridional (Claraz 2008:41).

Asimismo, y tal como afirma Palermo (1991), la exogamia o los matrimonios interétnicos no sólo resultaban importantes para las relaciones comerciales y políticas, sino que probablemente también entrañaban mecanismos de equilibrio demográfico. Algunos testimonios ayudan a respaldar esta hipótesis para los grupos aonikenk. Informa Schmid que las familias de los indígenas ubicados entre el río Santa Cruz y el estrecho de Magallanes (y con los cuales convivió durante algunos períodos entre 1858 y 1865) no son nunca numerosas; en término medio, dos o tres hijos forman toda la prole. Según lo que hasta ahora he podido ver, hay más varones que mujeres en estas tribus (Schmid 1964:183). Tres décadas más tarde, Ramón Lista también da cuenta de la notoria escasez de mujeres entre los aonikenk. Al observar los cuatro grupos australes y boreales que existían hacia la época lo primero que llama la atención es el escaso número de mujeres con relación a los hombres, a punto que puede decirse que para una de aquéllas hay tres de éstos. He aquí, entre otras, una de las razones capitales del decrecimiento de la población indígena (Lista 1879:59).

Puede conjeturarse que, debido a la escasez de mujeres en sus agrupaciones, algunos hombres aonikenk buscasen esposas fuera de su grupo, tal como lo hacían los hombres de otras parcialidades, en forma acordada o forzosa (cautivas) (Hernández 1837: 41, 50; Viedma 1837: 73; Cox 1999 [1863]: 157, 177-178; entre otros). De esta manera, mujeres pertenecientes a los grupos productores de tejidos podrían haber sido incorporadas como esposas a sus parcialidades, quienes mantuvieron algunas prácticas de su grupo de origen, entre ellas, la textil.
Como dato a tener en cuenta, Millán de Palavecino refiere que, luego de la Conquista al Desierto, y en las provincias del norte de la Argentina, los grupos y personas indígenas dispersos y asignados a las familias de las ciudades o ubicados en las propiedades rurales mantuvieron sus saberes y prácticas ancestrales. Esas prácticas perduraban hacia la época en que la autora realizó su trabajo de campo (década de 1960), cuando observó que: las mujeres ranquelinas, araucanas o pehuenches continuaron tradicionalmente en el aprendizaje impuesto por la madre: la construcción del telar araucano, los tipos de las técnicas, los métodos tintóreos y aún las substancias tintóreas que eran llevadas de lugares bien distantes hasta el sitio en que lo requería la tejedora. Tanto por este hecho comprobado, como por el idioma, que ha permanecido fiel al arte textil de los araucanos, se comprueba en este aspecto la persistencia de su cultura (Millán de Palavecino 1963: 423). A pesar del profundo cambio que implicó el traslado forzoso y el nuevo estilo de vida, las mujeres continuaron realizando aquellas labores que les eran propias en sus grupos de origen. Como afirma Boas al referirse sobre la incidencia del ambiente sobre las actividades humanas: puede demostrarse que antiguas costumbres, que pueden haber armonizado con cierto tipo de ambiente, tienden a sobrevivir en condiciones nuevas, donde representan más bien un obstáculo que una ventaja para un pueblo (Boas 1964:196). No debe extrañarnos, entonces, que las particularidades del estilo de vida y del territorio que habitaban los aonikenk no hayan sido impedimentos para la continuidad de la práctica textil entre las mujeres inmigrantes ni para la adopción de la misma por algunas mujeres aonikenk.

Pero si bien el desarrollo de la textilería entre los grupos aonikenk puede tener su origen en la enseñanza-aprendizaje efectuados en los momentos de los intercambios o en la incorporación mediante matrimonios de mujeres tejedoras provenientes de otras parcialidades, éstas no son las únicas posibilidades. Junto a los procesos referidos se producían con bastante asiduidad las rotaciones o pasajes de personal: individuos sueltos o grupos familiares podían abandonar sus tribus de origen e instalarse con otras, a la sombra de otros caciques, en razón de conveniencias particulares de variada índole. Y este paso no respetaba necesariamente 
las barreras étnicas (Palermo 1991: 177). Estas rotaciones son evidentes a partir del siglo XVIII y aumentan las referencias a las mismas en el siglo XIX. Como ejemplo paradigmático está el relato de Cox, quien halló entre los pehuenches cercanos al río Limay numerosos tehuelches y algunos guaicurúes viviendo entre ellos. Afirma este autor: Es muy difícil hacer categorías separadas por razas de los indios que viven desde la cordillera hasta el Atlántico, y desde los $35^{\circ}$ de latitud hasta el cabo de Hornos. Como los indios son muy errantes y viven en la compañía de los caciques que más les agradan, la homogeneidad de raza ha desaparecido. Para dar un ejemplo de esto, hablaremos de los que vivían en los toldos de Caleufu; Huincahual y Antileghen eran pehuenches, Inacayal, su hijo había nacido de una madre pampa, Agustín y Jacinto eran tehuelches; y el mocetón mordido por los perros era de origen huaicuru, tribu que habita cerca de Magallanes. Establecido aquí se casará; de él nacerán hijos que vendrán a aumentar la mezcla en las razas; la misma variedad se observa en las mujeres (Cox 1999 [1863]: 227-228). Agustín estaba casado con una tehuelche y vivía con su hija entre los pehuenches (Ibíd.: 199-200). Asimismo el autor refiere sobre una joven guaicurú llamada Callipai que era esclava de la mujer de Inacayal (Ibíd.: 225). Estas personas pertenecientes a distintas agrupaciones del sur y que no eran esclavos o cautivos, eran libres de regresar a sus parcialidades de origen en donde, seguramente, transmitirían los saberes adquiridos durante su residencia entre los grupos del norte.

También existen testimonios sobre araucanos, pampas, manzaneros, etc. viviendo entre los aonikenk (Moreno 1969 [1879]:342; Lista 1975[1881]:114115). Relata el Perito, hacia 1879, que En esta isla [Pavón] no encontramos novedades de ningún género. Los indios que han acampado frente a ella son los de Conchingan y los del cacique Gumberto; estos últimos vienen desde las inmediaciones del Nahuel-Huapi, a conocer los campos de Santa Cruz [...] Gumberto [...] como pariente de Shaihueque ha oído hablar de mi visita al campamento del Rey de las Manzanas (1969[1879]:394).

Un caso llamativo y quizás el más antiguo que refiere acerca de estas rotaciones o traslados de personas es el testimonio del padre Cardiel (asentado por el padre Lozano), quien buscando a un grupo de indígenas en las proximidades de la Bahía de San Julián en el año 1745, halló una casa, que por un lado tenía seis banderas de paño de varios colores, de media vara en cuadro, en unos palos altos, clavados en tierra, y por el otro lado cinco caballos muertos, embutidos de paja, con sus clines y cola, clavados cada uno sobre tres palos en altura competente. Entrando en la casa, hallaron dos ponchos tendidos, y cavando encontraron con tres difuntos, que todavía tenían carne y cabello. El uno parecía varón, y los otros mujeres; en el cabello de una de éstas había una plancha de latón de media cuarta de largo, y dos dedos de ancho, y en las orejas, zarcillos de lo mismo. En lo alto de la casa había otro poncho revuelto, y atado con una faja de lana de colores, y de ella salía un palo largo como veleta, de que pendían ocho borlas largas de lana amusca. Según estas señas, los difuntos eran de la nación Puelche (Lozano 1836 [1745]: 16-17). Y más adelante agrega Lozano: Lo que todos vinieron a concluir, reconocida esta tierra de la bahía de San Julián, y sus malas calidades, es que por allí no pueden habitar los indios por falta de leña, miel, caza, etc., sino que viven muy retirados; y discurrieron que el sendero estrecho que siguió el padre Cardiel cuatro jornadas es, o de los Araucanos de Chile, o de los Puelches y Peguenches, que vendrán tal cual vez por sal, de que carecerán en su país, a la laguna grande, o a las otras de la cercanía de la bahía; y que este año moriría allí algún principal de ellos, para cuyas exequias matarían dos de sus mujeres y sus caballos, para que les hiciesen compañía en la otra vida, según cree su ceguedad, y por el mismo motivo enterrarían con él todas sus alhajuelas. Maravillados sí quedaron, de que en tamaña distancia de Buenos Aires hubiese indios de a caballo, porque se juzga desde 150 leguas abajo, todos están de a pie, según nos dicen los indios serranos, y los derroteros de extranjeros. Según parece por sus alhajuelas de latón, etc., ellos tienen comunicación con otras naciones, que la tienen con españoles (Lozano 1836 [1745]: 20-21). La conjetura según la cual estas personas fallecidas y halladas en las cercanías de la Bahía San Julián pertenecerían a las agrupaciones araucanas, puelches o pehuenches parece acertada si tenemos en cuenta el relato del padre Havestadt (1930 [1752]), quien siete años después describió una ceremonia 
de enterramiento entre los indios pehuenches de Malargüe similar a la descripta por Cardiel en el sur de la Patagonia.

Alrededor de setenta años más tarde, Fitz Roy describe un enterramiento idéntico al de Cardiel y Havestadt en las proximidades del estrecho de Magallanes, el cual correspondía a la sobrina de la cacica o capitana María:

It was a conical pile of dried twigs and branches of bushes, about ten feet hight and twenty-five in circunference at the base, the whole bound riund with thongs of hide, and the top covered with a piece of red cloth, ornamented with brass studs, and bells, which, moved by the wind, kept up a continual tinkling.

A ditch, about two feet wide and one foot deep, was dug round the tomb, except at the entrance, which had been filled up with bushes. In front of this entrance stood the stuffed skins of two horses, recently killed, each placed upon four poles for legs. The horses' heads were ornamented with brass studs, similar to those on the top of the tomb; and on the outer margin of the ditch were six poles, each carrying two flags, one over the other (Fitz Roy 1839: 94).

Según se puede inferir del testimonio de Cardiel, a mediados del siglo XVIII y en lo que consideramos territorio aonikenk, se hallaban comitivas araucanas que incluían mujeres. Si bien las razones de tales desplazamientos nos resultan desconocidas (dudamos que se deba a la búsqueda de sal considerando la existencia de otras salinas más cercanas a sus territorios), resulta altamente probable que estos traslados incidieran en la expansión de algunos elementos de esa cultura en las regiones más australes de la Patagonia, entre ellos quizás el tejido.

Hasta aquí, entonces, se han presentado los testimonios hallados que refieren sobre la existencia de una práctica textil entre algunos grupos aonikenk, se han analizado algunas de sus particularidades que permiten asociarla con la tradición textil proveniente de los araucanos y se ha indagado acerca de los modos en que tal práctica pudo haber sido transmitida: durante las ocasiones en que los aonikenk comercializaban con los grupos araucanos o araucanizados en las regiones septentrionales de la Patagonia, a través de los matrimonios con mujeres de estas parcialidades y mediante las diferentes modalidades que adoptaron los traslados o rotaciones de perso- nas entre los distintos grupos. Indagaremos ahora sobre algunas características que adoptó la textilería entre los aonikenk y, estrechamente relacionado con ello, cuál fue el destino de su producción textil y las posibles razones de su adopción.

\section{ALGUNAS PARTICULARIDADES DE LA TEXTILERÍA AÓNIKENK: CONSIDERACIONES PREVIAS}

Millán de Palavecino (1963) ha argumentado que la adopción del tejido por los tehuelches habría respondido a la dificultad que comenzaron a tener para conseguir cueros a partir del establecimiento de las estancias en el territorio patagónico. Su hipótesis se fundamenta en el testimonio de una mujer tehuelche, oriunda de Río Mayo (Provincia de Chubut), hacia el año 1961: Otro hecho interesante y que se refiere a la economía, fue el mencionado por doña Agustina [Kilchamall], pues dijo, 'que el tejido fue aceptado por la escasez del cuero' frente a la mayor posibilidad de obtener lana de guanaco y de oveja. Y este hecho coincidía con la parcelación de las tierras de las estancias en el territorio del sur, pues era común que en el control del ganado, los tehuelches perdieran sus caballadas, que les eran marcadas por los nuevos pobladores (Millán de Palavecino 1963: 427).

El establecimiento de las primeras estancias patagónicas es posterior a las campañas de "Conquista del Desierto" (1879-1886), fecha más tardía a la de los testimonios referidos sobre la práctica textil en regiones más meridionales. De ello puede conjeturarse que la textilería fue adoptada en diferentes momentos por los distintos grupos indígenas ubicados al sur del Río Chubut. De esta manera, la parcialidad a la que pertenecía la informante de Millán de Palavecino habría incorporado tal práctica luego de la Conquista al Desierto y, por lo tanto, luego de los testimonios presentados y que refieren sobre los aonikenk. Es por ello que la escasez de cueros no debe considerarse la razón de la adopción de la textilería por los tehuelches: en primer lugar porque no debe considerarse a los tehuelches como un único grupo homogéneo, existiendo considerables diferencias entre las parcialidades denominadas de tal manera a pesar de contar con numerosos rasgos comunes que han permitido comprenderlas en un solo conjunto (Escalada 1949, Casamiquela 1965); 
en segundo término porque esta práctica textil al parecer sólo fue adoptada por algunas de esas parcialidades o lo hicieron en diferentes momentos, como ya dijimos; y en último lugar, porque algunas agrupaciones de los denominados tehuelches meridionales o aonikenk incorporaron la textilería en momentos en que contaban con importantes provisiones de cueros de guanacos y, en menor medida, de caballos y vacunos (Martinic 1995: 112-113). Si bien la carencia de cueros puede haber sido la razón principal de la incorporación de la textilería por el grupo de pertenencia de Agustina, tal motivo no debe hacerse extensivo a todas las agrupaciones comúnmente denominadas tehuelches.

Las adopciones de elementos foráneos a una cultura son el resultado de selecciones realizadas a partir de evaluaciones acerca de la conveniencia o no de esas incorporaciones, y que actúan en función de los intereses del grupo. Esos intereses llevan a elegir, de entre los variados rasgos de las culturas con las que entra en contacto, aquellos que puede emplear y descarta los que no le son utilizables. Y esta selección puede resultar fútil e incluso incoherente desde el punto de vista de un foráneo. El argumento de Agustina resulta lógico a nuestro modo de entender la realidad, a partir de nuestros patrones de pensamiento; sin embargo, para otros esquemas de comprensión basados en valores diferentes ello puede resultar inaceptable (Benedict 1971). El rechazo que los aborígenes pampeanos y patagónicos experimentaron por el consumo de cerdos (Palermo, 1991: 162) o la resistencia de algunos grupos patagónicos al consumo de pescado (Musters 2005 [1911]: 142; Coan 2006 [1880]: 51) son algunos ejemplos que ilustran esta idea.

Esto conduce a pensar que las razones para la adopción de elementos foráneos a una cultura pueden variar entre los grupos y da por sentado que el contacto entre culturas diferentes no es un motivo suficiente para fundamentar incorporaciones o cambios al interior de las agrupaciones. Muy probablemente todas las parcialidades aonikenk estuvieron en contacto, de alguna u otra manera, con los grupos araucanos o araucanizados; sin embargo, no todas incorporaron la práctica textil o al menos no lo hicieron al mismo tiempo. Asimismo, cuando elementos de una cultura diferente son incorporados, éstos sufren alteraciones en conformidad con las exigencias de la cultura a la que han sido integrados ${ }^{2}$. Todo elemento cultural se define a partir de patrones coherentes de acuerdo con las reglas (conscientes e inconscientes) de selección que se desarrollan dentro de esa misma cultura. Por lo tanto, si estamos interesados en conocer los motivos de un cambio cultural o la forma que adoptó un rasgo debemos ponerlo en relación con los valores instituidos en esa cultura y con los intereses que pueden estar relacionados con los ciclos de edades, el ambiente o las diversas actividades del hombre. Sólo podemos comprender una parte de la cultura si la analizamos en relación con el todo, es decir, con el ámbito del cual forma parte. Tal como lo afirma la psicología de la Gestalt, el conjunto determina sus partes; no solamente su relación, sino su naturaleza misma. Entre dos conjuntos hay una discontinuidad específica, y toda interpretación debe tomar en cuenta sus naturalezas diferentes, por encima del reconocimiento de los elementos similares que hay en ambos (Benedict 1971: 52-53).

La textilería fue un rasgo cultural común a algunos grupos aonikenk, a los denominados tehuelches septentrionales, a los pampas y a los araucanos hacia el momento histórico que nos ocupa, es decir, en el siglo comprendido entre 1780 y 1880. Pero si bien las particularidades técnicas más generales fueron las mismas y por ello puede considerarse a la tejeduría de esas parcialidades como pertenecientes a una misma tradición textil

2 Un buen ejemplo de ello es la adopción de la agricultura entre algunos grupos indígenas de las regiones pampeana y norpatagónica: Ya en la mitad del siglo XVII los pehuenche visitados por el $P$. Rosales, seguramente influidos por araucanos trasandinos, sembraban trigo y cebada, que complementaban a la recolección de los nutritivos piñones de araucaria. [...] en 1782 las exploraciones del español Basilio Villarino en la cordillera del centro del Neuquén revelaban proliferación de cultivos de trigo, cebada, habas, arvejas, chícharos, maíz, etcétera, entre los pobladores del lago Huenchulafquen (araucanos o araucanizados).

Sin embargo, debe tenerse en cuenta que el desarrollo de la agricultura era muy desparejo según los grupos; a la abundancia de cultivos recién anotada para la gente descrita por Villarino, se opone, sin ir más lejos, el caso de las bastante cercanas tribus del lago Nahuel Huapi (algo más al sur en la región cordillerana) visitadas diez años después por el $P$. Menéndez, quien nos explica en sus diarios que si bien consumían quinua [...] trigo y maíz, se limitaban a arrojar semillas en cercanías de los arroyos, sin cuidar el crecimiento de las plantas ni realizar cosechas sistemáticas (Menéndez 1900: 319). En otros casos, como el de los pampas bonaerenses, por ejemplo, se carece totalmente de agricultura en esta época (Palermo 1991: 164). 
(Méndez 2009a), no debe conjeturarse apresuradamente que tal arte tuvo las mismas características en cada una de esas agrupaciones. Para conocer esas características estimamos conveniente indagar en primer lugar sobre los tejidos que confeccionaron y los usos que dieron a los mismos. Esta indagación tiene importantes limitaciones debido a que excluye el estudio de la incidencia de los valores sobre las elaboraciones textiles, el cual resulta prácticamente imposible de realizar a partir de reconstrucciones póstumas (Benedict 1971). Sin embargo, ello no inhabilita el planteamiento de algunas hipótesis en base a los datos que disponemos, siendo ésta la manera fundamental de construcción del conocimiento histórico.

\section{ALGUNAS PARTICULARIDADES DE LA TEXTILERÍA AÓNIKENK: LAS REALIZACIONES TEXTILES Y SUS DESTINOS}

El primer testimonio sobre la confección de tejidos por los aonikenk y que corresponde a Antonio de Viedma, relata que tejían cintas de lana que empleaban para sujetarse el pelo doblado por arriba, con las puntas al aire como plumaje por el lado izquierdo, dándose con la cinta seis o ocho vueltas, y colgando las puntas de ella con unos cabetes de metal amarillo o latón [...][las mujeres] Llevan descubierta la cabeza, dividido el pelo en dos partes, y de cada una hecha una coleta, que baja por las orejas y hombros hasta el pecho $y$ cintura; cuya cinta es de lana parda de dos dedos de ancha, guarnecida, si es mujer rica, en días de gala con abalorios, y lo mismo las mujeres de alguna autoridad. (Viedma 1837: 69). Y a continuación informa que esas mujeres también empleaban las cintas o fajas tejidas en sus monturas: Ponen a la yegua un collar al cuello que cae hasta las rodillas, con cuantos cascabeles y colgajos pueden conseguir. Estos arreos son para gala y fiestas, pero en sus marchas ordinarias no usan estos adornos, $y$ en lugar de dicho collar ponen un cordón de lana azul o colorado, de un dedo de grueso, con el cual dan tres vueltas al cuello de la caballería, y los sirve también de estribo para montar en el sillón (Ibíd.: 71).

En cuanto a la referencia de Coan, en la traducción que disponemos sobre la descripción que este autor ofrece acerca del proceso de tejido, relata que lo que se está tejiendo es una colcha (Coan 2006 [1880]: 122); en la traducción ofrecida por Martinic, en cambio, se denomina a ese tejido jerga y se agrega: la operación [de tejido] es muy lenta requiriéndose cerca de dos semanas para concluir una de estas jergas: por consiguiente son muy escasas y nunca he visto media docena de ellas reunidas. Las que se hallan, se usan por lo general para enjaezar los caballos de los grandes (Martinic 1995: 259). Lamentablemente no hemos podido acceder al texto en su idioma original. A pesar de ello podemos asegurar que lo que se estaba confeccionando era una pieza para el apero de montar la cual en algunas regiones de la Patagonia es actualmente denominada matra y que era empleada -y aún lo es - como jerga y también como manta o colcha (Coan 2006 [1880]: 79; Musters 2005 [1911]: 91; Cox 1999 [1863]: 175; entre otros). Tal como asegura Fiadone El uso habitual de la matra como cobija o colchón [...] habrá hecho que a veces se confundieran los términos, y se usaron indistintamente para hacer referencia a la prenda y su uso ecuestre o a su adaptación doméstica (Fiadone 2007: 77). Las medidas que según Coan tenía el tejido eran de 1,30 metro de largo, lo cual coincide con el tamaño que generalmente tenían estas piezas (Taranto y Marí 2001: 92; Chertudi y Nardi 1961:159). Por su parte, Arms asegura que las mujeres aonikenk hacen cobertores con lana de guanaco que han coloreado a toda prueba y que sus maridos usan bajo sus monturas (Coan 2006[1880]: 199). Más tarde, Mendoza relata que las mujeres hacían mantas, fajas y cintas, sin ofrecer mayores detalles al respecto (Mendoza 1965: 63).

Hacia 1870, Musters refiere que las mujeres aonikenk tejían vinchas, fajas para la cintura y ligas para las botas de montar (Musters 2005 [1911]: 86, 194). Según este autor, las fajas realizadas por las aonikenk eran empleadas en su vestimenta para sostener su manta de guanaco y también en el apero, para ajustar la montura de las mujeres (Ibíd.: 96 y figura en página 95). D’Orbigny, en sus viajes realizados entre 1826 y 1833, informa que las mujeres indígenas de San Javier utilizaban una faja tejida como único estribo para montar, aunque no hace referencia a su elaboración (D’Orbigny 1998 [1843]: 784-785).

Por lo tanto, los aonikenk confeccionaron jergas que paralelamente fueron empleadas como 
mantas; también cintas que fueron utilizadas como vinchas, ligas para botas, estribos, arreos y fajas para la cintura que asimismo resultaron útiles para sujetar la montura de las mujeres. Algunos documentos dan cuenta de que los aonikenk también empleaban otras confecciones textiles tales como los ponchos:

A finales del siglo XVIII, Córdoba se encontró en reiteradas oportunidades con indígenas a caballo, de los cuales Uno hablaba muy poco el Español, de lo que se infirió había tenido bastante comunicación con nuestros establecimientos de la Costa Patagónica, pues nombraba algunas veces al Capitán Antonio Viedma, y al Piloto Bernardo Tafor: traía un Poncho de pañete de los que se fabrican en la Provincia del Río de la Plata, y su trage era el mismo que usan los criollos de la América Meridional, con sólo la adición de una especie de manta de pieles de Guanaco, cosidas entre sí, y en todo idénticas á las que venden los Indios en los establecimientos de la citada Provincia (Córdoba 1788: 20-21). Más adelante agrega que, en esa misma zona, en las proximidades del Cabo Vírgenes, los aborígenes vestían una manta de pieles de guanacos ó de zorrillos medianamente compuestas con rayas de diferentes colores en la parte interior [...] Algunos traen unos ponchos y calzones de igual género y hechura que los Criollos del Reyno de Chile y Buenos Ayres, no excluyendo este trage la manta de pieles. El poncho se reduce á una pieza de texido fuerte, rayado de diferentes colores de tres varas de largo sobre dos de ancho con una abertura en su mitad proporcionada para entrar la cabeza francamente [...] Algunos tenian ponchos de pañete de los de nuestras Fábricas de la Provincia de Buenos Ayres [...] Pocos eran los que disfrutaban de estas comodidades: lo mas estaban desnudos y reducidos á sus mantas de pieles y á una bolsa de cuero, que colgando de una correa que llevaban ceñida á la cintura les cubria sus partes vergonzosas (Córdoba 1788: 330-331). De estas descripciones se infiere que algunos nativos vestían ponchos, otros los empleaban como chiripá y se cubrían con las mantas de guanaco, y la mayoría utilizaba pieles a la cintura y la manta de guanaco como cobertor principal. Hacia la misma época, Viedma informa que entre los indios cercanos a San Julián, sólo las prendas de cuero utilizadas debajo de dicha manta fueron alternativamente reemplazadas por tejidos araucanos o telas industriales (Viedma
1837: 70). Alrededor de treinta años antes de estos testimonios, en 1752, Barne recibió información acerca de que a la altura de San Julián un cacique y algunos de sus acompañantes vestían ponchos y que los cuidaban mucho (Barne 1837:17). Consideramos que este último dato debe ser enmarcado por las descripciones antedichas, lo cual nos deja ver que el empleo de los tejidos en la vestimenta hasta fines del siglo XVIII parece ser más una excepción que una regla para los aonikenk.

En el año 1827, en su viaje al Estrecho de Magallanes, Fitz Roy relata que la vestimenta de los hombres y mujeres que se hallaban en las proximidades del Estrecho eran de pieles de guanaco. Al mismo tiempo describe la montura de uno de los hijos de la cacica María: One of the young men, whom we afterwards found to be a son of Maria, who was a principal person of the tribe, was mounted upon a very fine horse, well groomed, and equipped with a bridle and saddle that World have done credit to a respectable horseman of Buenos Ayres or Monte Video. The young man wore heavy brass spurs, like those of the Gauchos of Buenos Ayres (Fitz Roy 1839: 18). Y más adelante relata la manera en que María se presentó a ella misma: and stated herself to be sister of Bysante, the cacique of a tribe near the Santa Cruz River, who is an important personage, on account of his size (Vich Maria described to be immense), and his riches. In speaking of him, she said he was very rich; he had many mantles, and also many hides ("muy rico, tiene muchas mantas y tambien muchos cueros”) (Ibíd.: 86).

Se evidencia en estos relatos la importancia que tenía la montura y la posesión de mantos (de pieles de guanaco) y de pieles como símbolo de poder y status. Tales parcialidades estaban en contacto en forma directa o indirecta, con los centros comerciales criollos en donde tenían la posibilidad de adquirir tales monturas y también telas o textiles. Sin embargo, esto último no parece haber sido un elemento que otorgara prestigio a su portador, por lo menos en el momento y lugar al que hacemos referencia.

Menos de diez años más tarde, encontraremos en estas mismas agrupaciones próximas al estrecho la actividad textil descrita por Coan y Arms, en donde -vale recordarlo- se confeccionaban y empleaban tejidos para las monturas y para el abrigo, pero sin mencionar su uso en el vestir. Según estos autores, la vestimenta de los hombres y las mujeres 
con los cuales convivieron consistía exclusivamente de cueros (Coan 2006 [1880]: 60, 61, 79, 85, 197). Schmid, en su contacto con los aborígenes que habitaban entre el estrecho de Magallanes y el río Santa Cruz entre 1858 y 1861, comenta que su vestimenta más común, a la vez que la más primitiva, consiste en una capa hecha con pieles de guanacos jóvenes, blandas y suaves, con la que se cubren del cuello a los tobillos. También usan pieles de zorrinos, aunque esto es menos común [...] No faltan tampoco las de piel de liebre [...] Hombres y mujeres visten igual, pues la capa es la misma; la diferencia radica en el modo de usarla (Schmid 1964 171-172). Hacia la década de 1860, Musters afirma que entre los aonikenk la manta de piel amplia y abrigada suple a todas las demás ropas (Musters 2005 (1911): 193), y si bien sostiene que El traje de los hombres [aonikenk] consiste en un chiripá, con este término el autor no se refiere exclusivamente a una prenda tejida, sino que puede estar confeccionada por un poncho, o de un pedazo de tela, y también de piel de guanaco (Ibíd.). En su Viaje al río Chubut, realizado entre los años 1865 y 1866, Claraz informa que los indígenas de su partida (tehuelches meridionales y septentrionales) usaban siempre quillangos y que, ante un frío muy intenso, se colocaban un poncho encima de éste (Claraz 2008: 98, 106, 133, 135, 151). Además, realiza un comentario interesante al respecto: $E l$ carácter femenino se manifiesta en la constancia con que continúan la misma rutina, sin cambiar nada. En las mujeres esto es más fuerte que en los hombres. Se percibe en ello cierta gradación. El chileno, por ejemplo, ya se viste en forma parecida al gaucho, mientras que el pampa conserva su quillango. Más rutinario es aún el tehuelche. Y peor todavía son los fueguinos (Ibíd.: 87). En 1879 , Moreno relata que los hombres y las mujeres aonikenk que se hallaban en las proximidades del río Santa Cruz vestían quillangos (Moreno 1969 [1879]: 340). Hacia la misma época, Lista describe a la vestimenta de los hombres y mujeres de de las cercanías del río Chico de la siguiente manera: El traje de los hombres se compone de chiripá de algodón o de paño; una capa de pieles de guanaco, $y$ en ocasiones camisa y calzoncillos que compran en Punta Arenas o en Carmen de Patagones. Usan también tiradores con adornos de plata, vincha y botas de cuero de potro [...] Las mujeres visten comúnmente una especie de camisa de zarza o de lienzo, sin mangas, que las cubre de los hombros al tobillo, y sobre la cual llevan en toda estación la indispensable capa de pieles o de tela de lana (Lista 1975[1881]:115, 117). Hacia 1887, Del Castillo relata que en las proximidades del río Chico El vestuario de los hombres y de las mujeres está constituido por una capa de pieles que los cubre de cuello a pie, usando unos y otros camisas de tela (Del Castillo 1979: 41).

Por lo tanto, hasta la década de 1880, los aonikenk habrían empleado como vestimenta principalmente el manto de cuero, el cual eventualmente estaba acompañado por prendas de telas industriales o por tejidos aborígenes, una práctica que parece extenderse hasta bien entrado el siglo $\mathrm{XX}^{3}$. No hemos hallado referencias sobre la confección de ponchos por esta parcialidad, pero sí testimonios sobre la adquisición de éstos mediante intercambios o comercio con las agrupaciones araucanas o araucanizadas (Viedma 1938: 591; Musters 2005 [1911]: 91, 136; Coan, 2006 [1886]: 185; entre otros).

El hecho de utilizar los tejidos como jergas, vinchas, ligas, fajas, etc. y en escasa medida como vestimenta, puede haber tenido una razón simbólica que resulta difícil -si no imposible-corroborar en la actualidad. Sin embargo, es posible arribar a algunas conclusiones sobre la preferencia de los aonikenk por las mantas de guanaco en base a la favorable practicidad que ellas tenían para estos indígenas. Según Musters, las mantas de guanaco eran fáciles de secar luego de una lluvia, aunque siempre se debía tener cuidado de secarlas del lado del pelo para evitar resquebrajar el cuero (Musters 2005 [1911]: 122). Otro beneficio del empleo de

3 Si bien en el período inmediatamente posterior a esta década se generalizó el empleo de vestimentas foráneas obtenidas en los centros de intercambio, el quillango continuó siendo la prenda distinguible de los aonikenk (Martinic 1995 144-145). En los últimos tres años del siglo XIX, Hatcher informa que el quillango era la principal vestimenta de los indígenas que habitaban entre el río Santa Cruz y el estrecho de Magallanes. Asimismo, en la primera década del siglo XX, Onelli afirma que La raza tehuelche, que más o menos ha vivido siempre entremezclada con la araucana, debe haber aprendido de ésta el arte del telar, pues sigue servilmente sus dibujos y su urdimbre. Para los tehuelches es quizás un confort y una cultura obtenida tal vez hace menos de un siglo [...] Y más adelante agrega: el indio tehuelche jamás usa poncho: su abrigo favorito es el quillango de guanaco [...] (Onelli 1916: 47). 
los mantos de cuero puede haber sido la posibilidad de proteger la boca del portador con su pelo en los días de viento muy frío para evitar el dolor de encías, como también lo informa este autor (Ibíd.: 194). Para Claraz, los mantos confeccionados con pieles de guanacos jóvenes eran los más aislantes: Los animales que habitan en climas fríos tienen por naturaleza una protección apropiada. Entre los guanacos jóvenes, los intersticios entre los pelos están llenos de duvet, que por su constitución molecular y su contextura mecánica es uno de los peores conductores (Claraz 2008:203).

Asimismo, los quillangos parecen haber tenido la facultad de identificar la procedencia de las personas a la distancia, lo cual más de una vez pudo haber evitado algún infortunio. La experiencia relatada por Casimiro ilustra esta idea: Éste [Casimiro], al ver que se acercaban cinco indios montados, envueltos en sus ponchos, en la incertidumbre de si eran araucanos o tehuelches sacó el revólver, preparándose para despacharlos uno por uno; pero en seguida, con gran satisfacción, reconoció en el guía a un pariente suyo (Musters 2005 [1911]: 133). Cierta información que proporciona Cox puede ayudar a respaldar esta idea de la importancia del uso de los mantos de cuero como forma de identificación. Este autor relata que en las tolderías cosmopolitas de los pehuenches, en donde convivían aonikenk, tehuelches septentrionales, guaicurúes y cristianos, las mujeres realizaban las tareas propias de cada grupo: tejían a la usanza araucana y también preparaban cueros de guanaco según las técnicas tehuelches (Cox 1999 [1863]: 222). Al mismo tiempo, mantenían las costumbres propias de cada grupo en la vestimenta; las mujeres pehuenches vestían en forma similar a las araucanas mientras las mujeres tehuelches que vivían entre los pehuenches, a pesar de tener a su disposición prendas tejidas, sólo [usaban] cueros de guanaco como vestido, pero con los mismos adornos de las otras (Ibíd.: 223)4.

4 A partir de lo antedicho, resulta dudosa la aseveración de Vignati, según la cual, para las agrupaciones indígenas de la Patagonia meridional, Las prendas tejidas a mano, eran de mayor valor que los mantos de piel (cita número 50 en Mendoza 1965: 34). Ello puede resultar acertado si interpretamos que la valía de algunas de estas prendas era mayor que la de ciertas pieles al momento de los intercambios; pero si consideramos que la valía estaba en relación con el empleo de las mismas como vestimenta y abrigo, ello resulta erróneo para el caso de los aonikenk.
Tal como afirmamos en párrafos anteriores, la adopción de un elemento que forma parte de una cultura ajena no se realiza sin modificaciones: si bien los ponchos entre los araucanos eran utilizados como principal prenda de vestir y abrigo entre los hombres, y su uso estaba extendido entre los tehuelches septentrionales, no sucedía lo mismo con sus vecinos meridionales (Musters 2005 [1911]: 135). Estos, contrariamente a sus vecinos del norte y a los araucanos, emplearon escasamente los textiles como vestimenta. Sin embargo, los tejidos parecen haber sido ampliamente usados por los aonikenk como parte del recado al mismo que cumplían otras funciones: es así que fueron empleados como mantas y cojines (Musters 2005 [1911]: 91), como tapete para jugar a las cartas (Ibíd.: 208), para construír la casa bonita en donde se celebraban algunos ritos como los de nacimiento y entrada en la pubertad (Ibíd.: 100, 210, 224; González 1965: 23,29; Lista 1975[1881] 117-118), para envolver a sus muertos (Schmid 1964:184; Musters 2005[1911]: 211) y para rellenar sus armaduras (Musters 2005[1911]: 200).

La información que proporciona Millán de Palavecino resulta reveladora sobre este punto: luego de analizar junto a una tejedora tehuelche (Agustina Kilchamall) numerosas piezas textiles antiguas correspondientes a las parcialidades araucanas y tehuelches, esta autora determinó que los dibujos reconocidos por su asistente como propios de su cultura sólo estaban presentes en los tejidos empleados en la actividad ecuestre tales como las matras, matrones, caronillas y fajas (estas últimas empleadas como vestimenta y como estribo por las mujeres) y no se hallaban en otros tipos de prendas tejidas (Millán de Palavecino 1963: 427). Asimismo, a partir del testimonio de Agustina Kilchamall y de estudios etnográficos que esta autora realizó entre los araucanos del sur de la provincia de Neuquén y los ranquelinos de Azul y General Belgrano (provincia de Buenos Aires), pudo determinar que si bien las técnicas de ejecución de los textiles eran comunes a la proveniente de los araucanos, los temas decorativos

5 Otro ejemplo es el empleo que los aonikenk hicieron de los dedales entregados por los visitantes: contrariamente a ser empleados como protectores de los dedos en los momentos de costura de los cueros, según fue el objetivo de sus dadores, tales utensilios fueron usados y altamente codiciados por los aonikenk como adornos, quienes al parecer nunca los emplearon como protección (Coan 2006 [1880]: 66, 213). 
eran propios de cada una de estas parcialidades: El testimonio extenso sobre el tema dado por Doña Agustina involucra tambiénel valor de los selectivo, claro y determinante, de lo que ella reconoce como propiedad de su grupo en los dibujos textiles y reafirma una posición característica sobre esa condición entre los grupos etnográficos [...] En resumen, en áreas muy distantes se conserva este hecho propio entre los grupos etnográficos; el dibujo textil local pertenece al equipo patrimonial (Ibíd.: 429). Nuestro reciente estudio sobre los diseños textiles en las comunidades tehuelches y mapuches del centro-norte de la provincia de Chubut nos permite corroborar esta afirmación y agregar que dicha particularidad se conserva en esa zona hasta nuestros días (Finkelstein et. al. 2010).

Todo ello conduce a pensar que los tejidos elaborados por los aonikenk fueron aquellos empleados principalmente en la equitación, los cuales tuvieron paralelamente otros usos. Sus producciones textiles no fueron destinadas al vestir. Durante la época que nos ocupa, tanto los hombres como las mujeres aonikenk continuaron empleando la manta de piel de guanaco como principal abrigo, la cual combinaron con las manufacturas industriales y con las prendas salidas de los telares araucanos. Es posible especular, entonces, que la razón de la adopción de la textilería por algunos grupos aonikenk fue la confección de tejidos destinados principalmente a la equitación. Esto evidencia una selectividad en la incorporación y empleo de los elementos foráneos por la cultura aonikenk, como ya ha sido planteado. Si bien resulta claro que la realización de tejidos ha estado al alcance de tales agrupaciones (ya sea por aprendizaje mediante sus contactos con otros grupos o a través de matrimonios interétnicos o rotación de personal), no todas adoptaron tal práctica $y$, aquellas que lo hicieron, parecen haber producido sólo los tejidos que consideraron necesarios y que probablemente eran compatibles con sus valores.

\section{SÍNTESIS Y CONCLUSIONES}

Se ha mencionado en reiteradas oportunidades la importancia de considerar los intereses que habrían llevado a los distintos grupos indígenas a adquirir saberes y prácticas foráneas que fuesen más allá de las atribuciones al simple contacto con parcialidades culturalmente diferentes. En el caso de la expansión de la textilería entre los grupos patagónicos, si bien varios estudios han referido sobre los posibles orígenes de tal práctica, hasta el momento no se ha profundizado sobre los modos en que algunos grupos la incorporaron ni se ha indagado sobre las características que adoptó entre los aonikenk.

Hasta el momento, la hipótesis más extendida entre los estudiosos de la textilería, sostiene que la incorporación de la práctica textil entre los grupos tehuelches meridionales habría respondido a la carencia de cueros luego de la proliferación de las estancias en sus zonas de asentamiento. Sin embargo, la extensión de tal conjetura a todas las parcialidades al sur del río Chubut resulta invalidada por los testimonios que dan cuenta de la práctica textil entre algunos grupos de esa región desde finales del siglo XVIII. A partir de estos y otros documentos que no mencionan o niegan tales prácticas conjeturamos que la textilería habría sido adoptada en diferentes momentos por las distintas agrupaciones de esa zona y ensayamos algunas hipótesis explicativas sobre los modos en que tal práctica habría sido adoptada: una de ellas establece que la enseñanza-aprendizaje entre los grupos productores de tejidos y algunas parcialidades aonikenk se habría producido en los viajes que realizaban éstos al norte de la Patagonia y durante el tiempo que duraban las estadías en esa zona para efectuar los intercambios de productos entre las diferentes parcialidades. Aunque probablemente ello haya resultado dificultoso debido al prolongado tiempo que demanda esa tarea y a la reducida duración de las estadías.

Como explicaciones alternativas planteamos la exogamia y la circulación de personas entre los diferentes grupos como factores que hicieron posible la práctica textil entre algunos grupos aonikenk: las mujeres tejedoras provenientes de algunas agrupaciones del norte de la Patagonia que mediante acuerdos o raptos se integraron a algunas parcialidades aonikenk habrían sido las causales de la transmisión del saber textil entre ellos. De la misma manera, el asiduo traslado de familias enteras entre las distintas agrupaciones (posible gracias a la existencia de jefaturas laxas en toda la región durante la época colonial) también habría viabilizado la transferencia de ese saber. Respaldan estas últimas hipótesis los informes de algunos trabajos de campo realizados a mediados del siglo XX y recientemente, mediante 
los cuales se constató que a pesar de los cambios abruptos y profundos que implican los traslados a un medio y una cultura diferentes a los originarios de cada tejedora, las prácticas heredadas pueden mantenerse incluso en los casos en que el ambiente natural se torna hostil para el desarrollo de dichas prácticas.

También establecimos algunas particularidades de la producción textil aonikenk que nos permiten vincularla a la actividad ecuestre. El primer documento que refiere sobre la realización de tejidos entre los aonikenk -correspondiente a Antonio de Viedma- informa que tejían cintas empleadas en los tocados de las mujeres y también en sus monturas como collar y estribo. Esta primera referencia data de finales del siglo XVIII, escasas décadas después de las primeras informaciones sobre la existencia y el empleo de los caballos por miembros de esta parcialidad. Los documentos siguientes relatan que los aonikenk confeccionaban jergas y cintas que eran empleadas en la montura a la vez que fueron utilizadas como mantas, vinchas, ligas para botas y fajas para la cintura de las mujeres. No hemos hallado información sobre la elaboración de ponchos, alfombras $\mathrm{u}$ otros tipos de confecciones por esta parcialidad, aunque sí algunas referencias sobre la adquisición de los mismos mediante el comercio. Asimismo, el hecho de que los mantos de cuero (quillangos) continuaran siendo el vestido por antonomasia que los distinguió de sus vecinos del norte hasta el siglo $\mathrm{XX}$, y que el empleo de los textiles en la vestimenta haya sido circunstancial o esporádico, da a entender que la producción textil de los aonikenk no estaría orientada a la vestimenta.

A estas evidencias brindadas por algunos documentos históricos hemos sumado los resultados de los estudios etnográficos existentes hasta el momento y que refieren sobre las particularidades de la actividad textil en la Patagonia argentina. Ellos muestran dos cuestiones relevantes: que si bien la textilería de las regiones araucana, pampeana y patagónica posee una técnica común en su ejecución (y por eso puede considerársela dentro de una misma tradición textil), los dibujos realizados en los tejidos por cada agrupación son los de su patrimonio; y que los dibujos reconocidos como propios de la cultura tehuelche únicamente se han hallado en los tejidos empleados en los aperos y arreos. Todo ello respalda la idea de la estrecha vinculación existente entre dos adopciones que realizaron los aonikenk, al parecer, contemporáneas: la práctica textil y la equitación. De ello deducimos que, probablemente, la tejeduría fue adoptada por algunas agrupaciones aonikenk para realizar los tejidos destinados a la montura, aunque paralelamente recibieron otros usos.

Por lo tanto, la adopción del arte textil no fue instantánea ni producto del mero contacto entre las culturas diferenciadas, sino que implicó un proceso de selección y adecuación de la cultura receptora, que fue diferente de la realizada por otras agrupaciones al norte de la Patagonia. Los ponchos constituyeron las prendas de mayor relevancia, tanto en lo simbólico como en lo económico, para las parcialidades araucanas o araucanizadas y era una prenda fundamental en el vestuario de los hombres; sin embrago esto no sucedió entre los aonikenk, quienes son los deudores de su arte textil. Para ellos, los tejidos más usados y, al parecer los exclusivamente realizados en este período, fueron los empleados en la actividad ecuestre. A partir de ello, podemos afirmar junto a Benedict que cada cultura, en determinados momentos, explota unas pocas de un gran número de posibilidades sin que sea necesaria la carencia. La adopción de la tejeduría por los aonikenk no implicó un desplazamiento o menor desarrollo del trabajo en pieles y cueros, ni fue una consecuencia de la escasez de esas materias primas. Sino que fue una decisión basada en intereses vinculados a su recién incorporada actividad ecuestre.

Consideramos relevante poner en claro este proceso para evitar caer en la tentación de generalizar en una ley antropológica o sociológica los resultados de una combinación de rasgos local y única, suponiendo que su unión es un fenómeno universal. La cultura aonikenk no fue meramente la suma de sus partes (propias o adquiridas), sino el resultado de un único ordenamiento y de una única interrelación de las partes en donde la selección y adopción de nuevos elementos como la tejeduría y la equitación produjeron una nueva entidad a partir del siglo XVIII. 


\section{FUENTES CONSULTADAS}

Editadas:

BARNE, JORGE. 1837. Viage que hizo el San Martín, desde Buenos Aires al Puerto de San Julián, el año de 1752. En: Colección de viages y expediciones a los campos de Buenos Aires y a las costas de Patagonia. De Angelis, Pedro. Tomo 2. Imprenta del Estado. Buenos Aires.

BARTH, FREDERIK (compilador). 1975. Los grupos étnicos y sus fronteras. La organización social de las diferencias culturales. Fondo de Cultura Económica. México.

BOAS, FRANZ. 1964. Cuestiones fundamentales de Antropología Cultural. Solar/ Hachette. Buenos Aires.

BOCCARA, GUILLAUME Y GALINDO, SILVIA (editores). 2000. Lógica mestiza en América. Instituto de Estudios Indígenas Universidad de la Frontera. Temuco.

BOURNE, BENJAMIN. 2006 (1853). Cautivo en la Patagonia. Un norteamericano en la tierra de los "gigantes" (1849). Ediciones Continente. Buenos Aires.

BENEDICT, RUTH. 1971. El hombre y la cultura. Biblioteca fundamental del hombre moderno. Centro Editor de América Latina S.A. Buenos Aires.

CASAMIQUELA, RODOLFO. 1965. Rectificaciones y ratificaciones. Hacia una interpretación definitiva del panorama etnológico de la Patagonia y área septentrional adyacente. Universidad Nacional del Sur. Bahía Blanca.

CAVIGLIA, SERGIO. 2003. El arte de las mujeres aónik'enk y gününa küna -kay guaj'enk o kay gütrruj (las capas pintadas)-. En: Relaciones de la Sociedad Argentina de Antropología XXVII: 41-77.

CLARAZ, GEORGES. 2008. Viaje al río Chubut. Ediciones Continente. Buenos Aires.

COAN, TITUS. 2006 (1880). Aventuras en Patagonia. Un viaje de exploración de dos misioneros norteamericanos, Noviembre 1833 - Marzo 1834. Zagier \& Urruty Publications. Buenos Aires.

CORDOBA, ANTONIO DE. 1788. Relación del último viage al Estrecho de Magallanes de la Fragata de S. M. Santa María de la Cabeza en los años de 1785 y 1786 . Viuda de Ibarra, Hijos y Compañía. Madrid.

COX, GUILLERMO. 1999 (1863). Viaje en las regiones septentrionales de la Patagonia, 1862-1863. Imprenta Nacional. Santiago de Chile.

CHERTUDI, SUSANA Y NARDI, RICARDO. 1961. Tejidos Araucanos de la Argentina. En: Cuadernos del Instituto Nacional de Investigaciones Folklóricas, (2):97-182.

DEL CARRIL, BONIFACIO. 1992. Los indios en la Argentina. 1536-1845. Emecé. Buenos Aires.
DEL CASTILLO, AGUSTÍN. 1979. Exploración de Santa Cruz y Costas del Pacífico. Marymar. Buenos Aires.

DELLEPIANE CÁLCENA, CARLOS. 1960. Consideraciones sobre la tejeduría de una comunidad de origen araucano. En: Cuadernos del Instituto Nacional de Investigaciones Folklóricas (1):83-93.

D'ORBIGNY, ALCIDE. 1998 (1843). Viaje por América Meridional. Tomo II. Emecé. Buenos Aires.

ESCALADA FEDERICO. 1949. El complejo tehuelche. Estudios de etnografía patagónica. Imprenta y casa editora Coni. Buenos Aires.

FIADONE, ALEJANDRO. 2007. Simbología Mapuche. Maizal Ediciones. Buenos Aires.

FITZ ROY, ROBERT. 1839. Narrative of the surveying voyages of his majesty's ships Adventure and Beagle between the years 1826 and 1836. Vol.1. J. L. Cox and Sons. London.

GONZÁLEZ, FRANCISCO. 1965. Diario del viaje que hizo por tierra de Puerto Deseado al río Negro. 1798. Academia Nacional de la Historia. Buenos Aires.

GUARAVAGLIA, JUAN CARLOS. El poncho: una historia multiétnica. En: Colonización, resistencia y mestizaje en las Américas. Siglos XVI-XX. Boccara, Guillaume. Editorial Abya Yala/IFEA. Quito.

GUINNARD, AUGUSTE. 2006. Tres años entre los patagones. Ediciones Continente. Buenos Aires.

HADJUK, ADAM. 1981-1982. Algunos antecedentes arqueológicos de los mapuche en la Argentina. En: Cultura Mapuche en la Argentina. Instituto Nacional de Antropología pp. 7-29.

HATCHER, JOHN. 2003. Cazadores de huesos en la Patagonia. Zagier y Urruty Publications. Ushuaia.

HAVESTADT, BERNARDO. 1930 (1752). Viaje de fray Bernardo Havestadt al Neuquén. En: Neuquén. San Martín, Félix. Biblioteca del Suboficial. Buenos Aires.

HERNANDEZ, JUAN ANTONIO. 1837. Diario que el capitán, don Juan Antonio Hernández ha hecho, de la expedición contra los indios teguelches, en el gobierno del señor don Juan José de Vertiz, gobernador y capitán general de estas Provincias del Río de la Plata, en $1 .^{\circ}$ de octubre de 1770. En: Colección de viages y expediciones a los campos de Buenos Aires y a las costas de Patagonia. De Angelis, Pedro. Tomo 2. Imprenta del Estado. Buenos Aires.

JENKINS, RICHARD. 1996. Social identity. Routledge. Londres. JOSEPH, CLAUDE. 1931. Los tejidos Araucanos. Imprenta San Francisco, Padre Las Casas. Santiago de Chile.

KERMES, ENRIQUE. 1893 Tejidos Pampas. En: Revista del Jardín Zoológico de Buenos Aires, 1(4):178-187. 
LEÓN SOLÍS, LEONARDO. 1989-90. Comercio, trabajo y contacto fronterizo en Chile, Cuyo y Buenos Aires, 1750-1800. En: Runa XIX: 177-221.

LISTA, RAMÓN. 1879. Viaje al país de los Tehuelches. Exploraciones en la Patagonia Austral. Imprenta de Martín Biedma. Buenos Aires.

-1975 (1881). Mis exploraciones y descubrimientos en la Patagonia, 1877-1880. Marymar. Buenos Aires.

LORENZO, JOSÉ; MURGA, GONZALO Y FERREIRO, MARTIN. 1864. Diccionario Marítimo Español. Establecimiento Tipográfico de T. Fortanet. Madrid.

LOZANO, PEDRO. 1836. Diario de un viaje a la costa de la mar magallánica en 1745, desde Buenos Aires hasta el Estrecho de Magallanes. Formado sobre las observaciones de los PP. Cardiel y Quiroga. En: Colección de obras y documentos relativos a la Historia Antigua y Moderna de las provincias del Río de La Plata. De Angelis, Pedro. Tomo 4. Imprenta del Estado. Buenos Aires.

MANDRINI, RAÚL Y ORTELLI, SARA. 2006. Las fronteras del Sur. En: Vivir entre dos mundos. Las fronteras del sur de la Argentina. Siglos XVIII y XIX. Mandrini, Raúl. Nueva Dimensión Argentina. Buenos Aires.

MARÍ, JORGE Y TARANTO, ENRIQUE. 2001. Textiles de uso tradicional. Asociación Criolla Argentina. Buenos Aires.

MARTINIC, MATEO. 1995. Los Aónikenk, historia y cultura. Ediciones Universidad de Magallanes. Punta Arenas.

MENDEZ, PATRICIA. 2009a. Herencia textil, identidad indígena y recursos económicos en la Patagonia Argentina. En: AIBR, Revista de Antropología Iberoamericana, 4(1):11-53.

-2009b. Los tejidos indígenas en la Patagonia Argentina: cuatro siglos de comercio textil. En: Indiana, 26: 233-266.

MENDOZA, DOROTEO. 1965. Diario y memoria del viaje al Estrecho de Magallanes 1865-1866. Academia Nacional de la Historia. Buenos Aires.

MILLAN DE PALAVECINO, MARÍA DELIA. 1932. Tejidos araucanos del Neuquén. En: XXVo Congreso Internacional de Americanistas realizado en la Universidad Nacional de La Plata (Buenos Aires) en 1932, 1:215-222. -1963. Area de expansión del tejido araucano. En: Primer Congreso del Area Araucana Argentina realizado en San Martín de los Andes (Neuquén) del 18 al 24 de Febrero de 1961, 2:411-448.

MORENO, FRANCISCO. 1969 (1879). Viaje a la Patagonia Austral. Solar/ Hachette. Buenos Aires.

MUSTERS, GEORGE. 2005 (1911). Vida entre los Patagones. El Elefante Blanco. Buenos Aires.

ONELLI, CLEMENTE. 1977 (1904). Trepando Los Andes. Ediciones Marymar. Buenos Aires.
-1916. Alfombras y tapices. Tejidos criollos. Ediciones Guillermo Kraft. Buenos Aires.

ORTELLI, SARA. 1996. La araucanización de las pampas: ¿realidad histórica o construcción de los etnólogos? En: Anuario del IEHS (11): 203-225.

PALERMO, MIGUEL ANGEL. 1991. La compleja integración hispano-indígena del sur argentino y chileno durante el período colonial. En: América Indígena, 51(1):153-192. -1994. Economía y mujer en el sur argentino. En: Memoria Americana (3):63-90.

SCHMID, TEÓFILO. 1964. Misionando por la Patagonia Austral. 1858-1865. Academia Nacional de la Historia. Buenos Aires.

VIEDMA, ANTONIO DE. 1837. Diario de un viage a la costa de Patagonia para reconocer los puntos donde establecer poblaciones. En: Colección de obras y documentos relativos a la historia antigua y moderna de las provincias del Río de la Plata. De Angelis, Pedro. Tomo 6. Imprenta del Estado. Buenos Aires.

VIEDMA, FRANCISCO DE. 1938. Informe al Virrey Vértiz, del 13 de Octubre de 1783. En: Revista de la Biblioteca Nacional, II (7): 588-602. Buenos Aires.

VIGNATI, MILCÍADES s/f Etnografía y Arqueología. Usos, costumbres y cultura de los aborígenes de Buenos Aires, La Pampa y Patagonia: Período Colonial. En: Historia Argentina 5. Plaza y Janés S.A. Buenos Aires.

WILSON, ANGÉLICA. 1992. Arte de Mujeres. En: Colección Artes y Oficios, 3. Ediciones CEDEM. Santiago de Chile.

Inéditas:

FINKELSTEIN, DÉBORA. 2008. Artesanías de alta Calidad con diseños basados en la cultura e identidad comarcal. Consejo Federal de Inversiones. Informes finales de trabajo: agosto de 2006, febrero de 2007, febrero de 2008. MS.

FINKELSTEIN, DÉBORA, MENDEZ, PATRICIA Y NOVELLA, MARÍA MARTA. 2010. Informe de investigación sobre los diseños textiles en la Comarca de la Meseta Central de la provincia de Chubut para la Secretaría de Ciencia y Técnica del Ministerio de Educación. MS.

GOMEZ OTERO, JULIETA s/f. Las artesanías tehuelches y su evolución desde 1520 hasta comienzos del siglo XX. Primera Parte. MS.

IRUSTA DE BENBASSAT, DELIA. 1986. Trabajo de campo Area Educativa Gastre (DPC-CPE). Informe para el Departamento de Investigación y Conservación. Rawson.

MENDEZ, PATRICIA. 2009c. Informe de investigación sobre algunos aspectos de la cultura aonikenk: sombreros y monturas. MS. 